This item was submitted to Loughborough's Research Repository by the author.

Items in Figshare are protected by copyright, with all rights reserved, unless otherwise indicated.

\title{
Absent apologies
}

\section{PLEASE CITE THE PUBLISHED VERSION}

http://dx.doi.org/10.1080/0163853X.2015.1056690

\section{PUBLISHER}

(c) Taylor and Francis

\section{VERSION}

AM (Accepted Manuscript)

\section{PUBLISHER STATEMENT}

This work is made available according to the conditions of the Creative Commons Attribution-NonCommercialNoDerivatives 4.0 International (CC BY-NC-ND 4.0) licence. Full details of this licence are available at: https://creativecommons.org/licenses/by-nc-nd/4.0/

\section{LICENCE}

CC BY-NC-ND 4.0

\section{REPOSITORY RECORD}

Drew, Paul, and Alexa Hepburn. 2019. "Absent Apologies”. figshare. https://hdl.handle.net/2134/18347. 


\section{Absent apologies}

Paul Drew

Department of Social Sciences, Loughborough University UK

Alexa Hepburn

Department of Social Sciences, Loughborough University UK

Corresponding author:

Paul Drew

Department of Social Sciences

Loughborough University

Loughborough LE11 3TU

Leicestershire

UK

Email: p.drew@lboro.ac.uk

Tel: +44 (0)1509-263171

Running head: Absent apologies

Forthcoming in Discourse Processes, special issue on apologising (eds. P.Drew, R.Galatolo, A.Hepburn and P.Margutti) 
Introduction

When Jefferson made the data search that resulted in the corpus of apologies on which this paper is based, she included in her first trawl instances of anything that might be related to apologising, any sequence of talk in which one person said they were sorry or in which they appeared explicitly, implicitly or indirectly to be apologising. That's what one does in a data search to collect instances of some phenomenon - trawl through data to catch whatever might be relevant, or in the ballpark. Subsequent review and analysis of the data enables one to refine the parameters of the phenomenon, to identify which are and which are not instances of the phenomenon, and to discard data examples collected in the first trawl that, on closer inspection, turn out not to be relevant to the emerging analysis of that phenomenon. So for instance Jefferson included this example in her initial data run for apologies.

(1) [NB:IV:4] (Emma has called her sister, Lottie, to tell her that her husband has 'walked out' on her)

$\begin{array}{lll}1 & \text { Lot: } & \text { Gee I'm sorry tuh hear tha:t, } \\ 2 & \text { Emm: } & \text { Well don'let it upsetchu. } \\ 3 & \text { Lot: } & \text { hYeah,h }(.) \text { I have this all the ti:me so what }{ }^{\circ}{ }^{\circ}{ }^{\circ} \\ 4 & & \text {.hhh }(0.2) . \text { kh I'm the one that wa:lks OU:T. }\end{array}$

It's pretty clear how this came to be included in the initial data trawl for apologies; but when in line 1 Lottie says "I'm sorry" to hear about Emma's marital troubles (highlighted), she is not apologising; she has nothing to apologise for (and that will become relevant as we proceed here). She is expressing her regret, on Emma's behalf, for Emma's trouble and distress (see also Robinson 2004: 316-319). Moreover, Emma does not respond (in line 2) as though Lottie had apologies; she does not absolve her of any wrongdoing but rather comforts her. So this and other instances like it were discarded.

However, among the curiosities that were included in Jefferson's data trawl were several instances of the following kind of sequence.

(2) [Rahman:1:2:1] (Jessie is calling her optician; having called at their premises in last week, she expected them to call back to make an appointment. The receptionist has now put Jessie through to the optician, Fortis)

$\begin{array}{lll}1 & \text { Fortis: } & \text { Hello::: } \\ 2 & \text { Jessie: } & \text { Hello? } \\ 3 & \text { Fortis: } & \text { I tried tuh ring you on: Thursday evening.=b't I couldn' } \\ 4 & & \text { get'ny reply::. } \\ 5 & \text { Jessie: } & \text { Oh dea:r. ehh hnh[h } \\ 6 & \text { Fortis: } & \text { ['T's alright [Now? }\end{array}$

Neither Jessie nor the optician apologises here; but in line 6 Fortis responds to Jessie's prior turn (in line 5) as though she had apologised. We will explicate how this is apparent as we proceed; for the present we'll simply note that responding to the other as though they had apologised, although the co-participant had not done so, 
suggests that Fortis might have expected an apology, which however was not made and is therefore absent.

Absent apologies - apologies that were expected but which are not forthcoming - are quite frequently identified and commented upon, for instance in the media. We have a large collection of newspaper reports about refusals by public figures (in politics, sport, commercial and celebrity life) to apologise for what others have regarded as transgressions; one example will have to suffice to illustrate what's at stake in such instances. This occurs in a report concerning a politician representing the Liberal Democrats in the UK's Houses of Parliament (House of Lords), Lord Rennard, who has been accused by four women LibDem MP's of his "sexually inappropriate behaviour".

(3) [From the Guardian newspaper, $26^{\text {th }}$ July 2014, p.9]

“An inquiry by Alistair Webster QC into the women's claims found they were credible but concluded there was not sufficient evidence that Rennard had acted in a sexually inappropriate way to bring any disciplinary charges. He did, however, raise the possibility that the peer might "reflect upon the effect his behaviour has had and the distress which it caused and that an apology would be appropriate. After refusing to do so, Rennard was suspended over whether his failure to say sorry brought the party into disrepute. Rennard, who has always denied touching the women inappropriately, finally said sorry in May -15 months after the original claims - if he inadvertently encroached on the women's personal space."

This newspaper report suggests a number of features, some of which will be developed in our analysis here; a transgression is made explicit but contested (denied); an apology would be appropriate, but is not forthcoming; an apology is given but delayed. ${ }^{1}$ Underlying this report is the sense that an apology might be expected, but is withheld by the putative transgressor ("After refusing to [apologise] . ..”). This is surely a common enough experience in ordinary social life, that one considers that one is owed an apology, which is not proffered. An apology was expected, but is absent. The challenge is to show where and how apologies might have been expected, but were not forthcoming, given that all we can see as analysts, unable to read the participants' minds, is that an apology was not made. This parallels other work in Conversation Analysis (CA) on actions or objects that might be 'missing' in ordinary interactions, on (noticeable) absences (e.g. Atkinson \& Drew 1979: 52-57, Goodwin 1980, Schegloff 1988: 120-122), including the non-correction by a recipient of a speaker's error (Jefferson 1987). The challenge is to show empirically, in the data, not just that something was not done, but that it was relevantly not done, or that it's not being done was noticeable and salient to the participants at the time - in Jefferson's (1987) study, that the absence of a correction was "restricted to cases of observably relevant error that does not get 'corrected' (Jefferson 1987: 2; her emphasis). We are exploring here the evidence for an apology being absent, and being relevantly or even noticeably absent for participants in the interaction.

\section{The construction of apologies: components of turn design}

It is characteristic of apologising that, in contrast to most (all?) other 'speech acts', apologies need to be made explicitly (Edmondson 1981; Robinson 2004), and 
moreover verbally. An apology requires a speaker to say 'I'm sorry ...,', 'I apologise . ..' or 'My apologies ...' or 'Many apologies ...' or something from this pretty restricted class, using the words 'sorry' or 'apology' (see ex. 3 above, and references to "said sorry"). Other actions conducted in interaction may be done entirely nonverbally (see Rossi 2015, on requesting non-verbally), or indirectly (reference on indirection) or without using a performative verb (e.g. Would you like mine? as an offer). But without being verbally explicit that one is apologising, by using the words sorry or apologise, an apology has not been made, it is not 'on the record'.

This begins to focus our attention on the design of apologies that are made, which can be as brief as the single word "Sorry," usually as an apology for committing a minor transgression, inadvertently, in a face-to-face encounter. Otherwise, apologies are constructed in broadly two other formats. In the first, apologies are composed structurally of two components, [Apology word or phrase] + [Transgression]. Here is an example:

(4) [Deutsch:CDII:88-89] (Two couples are sitting eating and drinking; Nancy suddenly realises that she's picked up and is drinking from her boyfriend's wine glass)

1 Nancy:

Oh so(h)rr(h)y (h) uhm drin[kin yer whi] $]$ (h)[ne

Vivian: [ehh heh heh ] [You [w a n t=

Nancy:

Vivian:

$=\mathrm{s}^{\prime} \mathrm{m}$ more Nance?

$\left[{ }^{\circ}\right.$ uhh! ${ }^{\circ}$

Here the [Apology] component (prefaced with oh in ex.4, on which see Pino et al, this issue) is followed by a component in which the nature of the transgression is 'named, 'drinking your wine' (in some instances the order of these components is reversed).

Notice also that not only is the transgression named but it is also admitted by the speaker/transgressor, as 'I'm drinking ...'2 and 'I've kept . . .'. So this component might best be described as [Transgression/Admission].

Quite commonly the design of the apology turn includes a third component, an [Account], as here.

(5) [Truancy office:JPP:1:1] (High school truancy officer TO calling the home of student)

1 TO: Uh w'z Bra:d home fr'm school i:ll t'da:[y?

2 Mrs R:

[Ah::: yes he was in fact,

3 I'm sorry I I didn' call becuz uh: I slept in late I $(\cdot)$ haven't been

4 feeling well either, hhhh and uh: hh (0.4) he have a:m yihkno:w a:,

5 fever:: (·) this morning.

The three components in (5) - [Apology] + [Transgression/Admission] + [Account $]$ have been highlighted; as is quite general for accounts, the [Account] is formed as some circumstance that prevented the speaker doing something (i.e prevented Mrs R. 'calling'). Heritage and Raymond (this issue) examine the construction of apologies more fully, but for our present purposes this outline is as much as we need.

The negotiation of culpability 
In Mrs R's accounts in (5) we begin to see that matters of responsibility, fault or culpability are being addressed; whilst the speaker is admitting to a failure (to call), nevertheless she represents herself as not wholly responsible and therefore culpable. Mrs R explains that she 'didn't call' because she 'slept in late', adding that this was because she also was unwell (lines 3-5). The accounts that can accompany apologies begin to reduce the culpability or fault that may be attributed to the speaker, in marked contrast to this example.

(6) $[\mathrm{SF}: 2: 2]$ (Brad has heard from a mutual friend that Tom is having a party Friday - which he "wasn't clued in on", i.e. hasn't received an invitation)

$\begin{array}{lll}1 & \text { Tom: } & (\quad) \text { I'm sorry, h } \\ 2 & & (0.7) \\ 3 & \text { Brad: } & {[\cdot h h h} \\ 4 & \text { Tom: } & {[\text { But }-(\cdot) \text { yih know how these things a:re, h }} \\ 5 & & (0.7) \\ 6 & \text { Brad: } & \text { 't }(\text { How are }), h \\ 7 & \text { Tom: } & \text { Oh:. Well,hh }(\cdot) \text { No uh hist a matter'v,hh }(0.4) \cdot \text { hhhhhhh taking } \\ 8 & & \text { fer grannid thetchu know you know it's ar fault theh you don't } \\ 9 & & \text { know. }\end{array}$

Having apologised (line 1) for not letting Brad know about the upcoming party, Tom begins to embark on a kind of account or excuse, 'you know how these things are' (line 4). It's not clear whether in response (line 6) Brad 'questions' or mimics in some fashion Tom's idiomatic excuse, but at any rate Tom explicitly repairs that excuse "Well,hh (.) No ..." (line 7) and instead admits quite directly that he 'took for granted' that Brad would know and therefore that "it's ar fault theh you don't know," thereby fully accepting responsibility for the failure. By contrast, in her account in (5) Mrs R mitigates her responsibility and therefore culpability for her transgression.

In this respect, then, 'how much' is being admitted and the extent to which the speaker is admitting responsibility or accepting they are at fault in apologising is being negotiated through the accounts that may accompany apologies. The negotiation of culpability is evident in (at least) two other aspects of the design of the apology turns. The first is the design of the [Transgression/Admission] component, in which speakers commonly name or specify the transgression, as was shown in (4) ('I'm drinking your wine'). However, in other cases the apology is accompanied by only a general, often deictic reference to the transgression.

(7) [Holt:SO88:1:1:4-5] (Children can be heard making a noise outside; William has asked Gordon to 'hold on a minute' while he goes to 'tell these kids to shut up)

1 William:

Oy:. Shut up. (

$(\cdot)$

Gordon: hh:hhowhh

William: $\quad$ Sorry abo[ut that

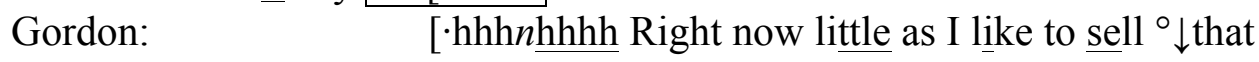
acoustic guitar ... 
[Holt:88U:1:4:1] (Gordon phoned Dana late the previous night; she was out, her mother answered, and Gordon was drunk)

1 Gordon: Hey listen I'm sorry about last ni:ght, $\cdot \mathrm{h} m \mathrm{hh}$

2 Dana: Mm:

In each of these examples, there is no specific [Transgression/Admission] component. Although in (7) William is apologising for interrupting their conversation to deal with some noisy interference, and in (8) Gordon is apologising for having called so late at night, these transgressions are not made explicit; they are implicit in deictic references to 'about that' in (7), and 'about last night' in (8). The deictic 'that' and the time reference 'last night' are unspecific - they do not specify what 'that' is or what it is about 'last night' for which they are apologising (for more on indexical references to transgressions see Margutti et al. this issue). So apologies are made for transgressions that are unstated, inexplicit, unnamed. These speakers are not admitting to anything specific or 'on the record,' which works to reduce the fault.

The second aspect of the design of apology turns that works to reduce the speaker's fault or culpability is a recurrent and significant feature of the design of the account that accompanies many apologies. Broadly speaking, accounts may be designed to attribute some responsibility, even fault, to a third party.

(9) [NB:VII:1] (his is the beginning of the call. Emma is apologising for having kept for too long a power tool that her husband borrowed from Margy's husband. Emma makes a jokey introduction/self-identification; without giving her name, she says that 'We do painting, antiquing ...' then in line 1 'keep people's power tools')

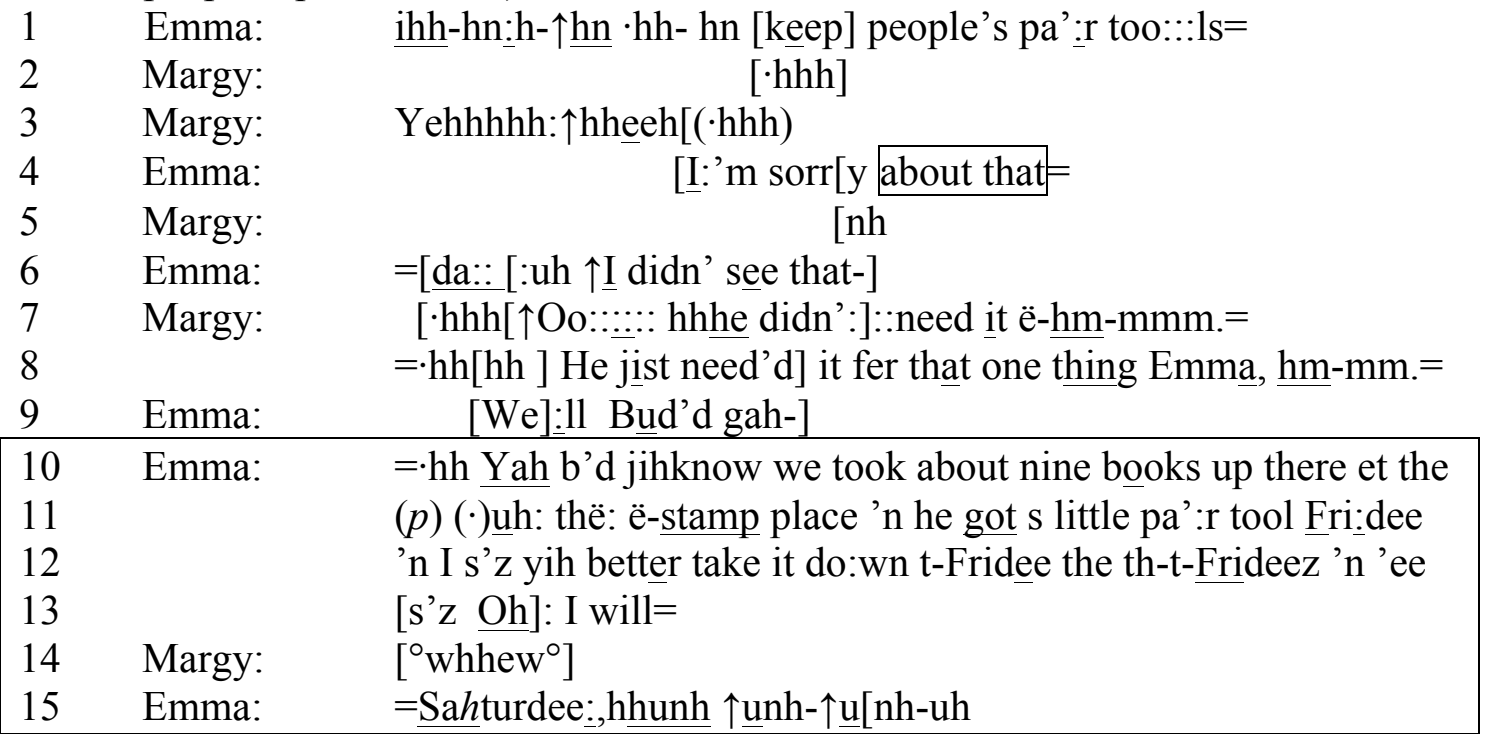

Whilst Emma makes an admission of sorts in line 1, 'keep people's power tool,' that admission is packaged in her humorous introductory self-identification. She then makes only a deictic reference to the transgression for which she is apologising ('about that', highlighted in line 4). Her first attempt to add an account, in line 9, is cut off, presumably by finding herself talking in overlap with Margy; but already it is evident that 'Bud', Emma's husband, will feature in her account, as he does in her account in lines 10-15. In her account Emma suggested that Bud get a power tool of 
his own on Friday, ${ }^{3}$ in order to be able to return the one they had borrowed; but he procrastinated ('and he says oh I will Saturday,' lines 12-15). In other words, the transgression, keeping the power tool so long that Margy's husband has had to ask for its return, would not have occurred had Bud listened to her (Emma). Her account is built to attribute responsibility and therefore culpability not to herself but to a third party, her husband.

This means of shifting responsibility onto another person is evident also in the next example, which shows more fully the interaction from which ex.8 was taken. This begins close to the beginning of the call; the background is that Gordon phoned Dana's home very late the previous night, expecting to speak to Dana; however Dana was still out with friends, so Gordon spoke instead to her mother - and Gordon was drunk.

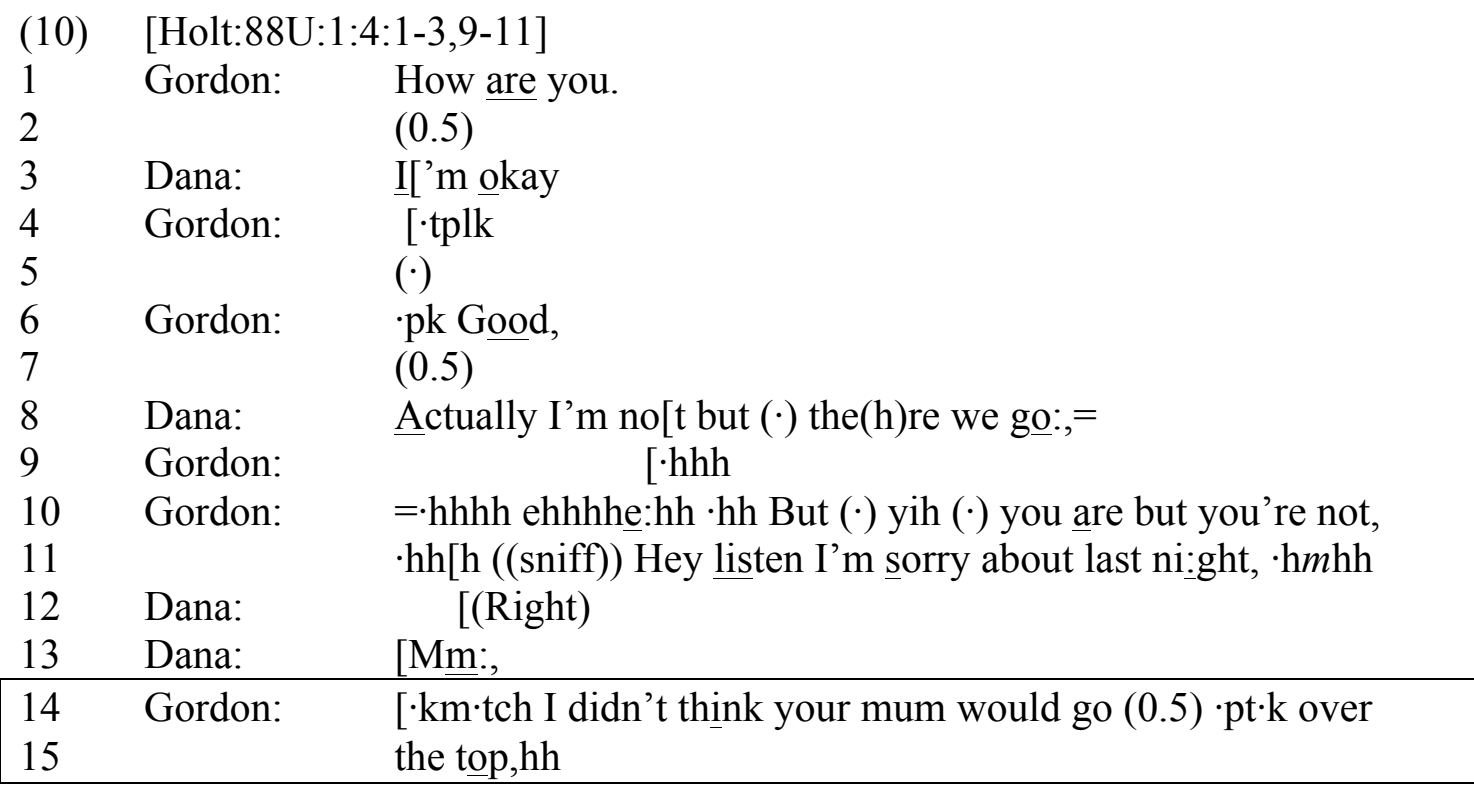

Dana responds to Gordon's 'How are you' with a downgraded form in line 3 ('I'm okay') which portends trouble (Jefferson 1980). This implicit indication of trouble comes to the surface in her revision ('Actually ... ', Clift 2001), in response to which Gordon apologises 'about last night', which as we have seen does not specify the transgression for which his apology is being made. Furthermore, in his account in lines 14-15 Gordon shifts responsibility to Dana's mother, for overreacting ('go over the top' being an idiomatic expression for an extreme or unreasonable reaction; in a subsequent version of this apology he says that "I didn't think she'd uh $(\cdot)$ she'd panic").

These impersonal constructions, achieved through deictic references to whatever the speaker is apologising about, elide matters of agency, and in that way reduce the responsibility or culpability that may be attributed to the speaker. Likewise, accounts in which some degree of responsibility is attributed to a third part, as in (9) and (10), also deflect responsibility and a degree of culpability from the speaker. The design or construction of apologies and their constituent components, then, is associated with the attribution and negotiation of responsibility, fault (transgression) and culpability. From which it follows that when someone does not apologise, they are denying that they have committed a transgression, and therefore any measure of fault. Apologies 
are acknowledgements of some wrongdoing and fault, though the degree to which speakers admit to responsibility and culpability for some transgressions is a negotiable property. Non-apologies, or the absence of apologies, pretty clearly manifest someone's disclaiming wrongdoing and fault. But of course their coparticipants may not agree, may not align with the other's sense of innocence.

\section{Delayed apologies}

An indication that participants may differ over the matter of whether one of them has transgressed, or has committed a virtual offence, and whether an apology is due can be found in cases where an apology is not forthcoming at a first or early opportunity, and is only made after some pursuit by the other, as happens in ex.11.

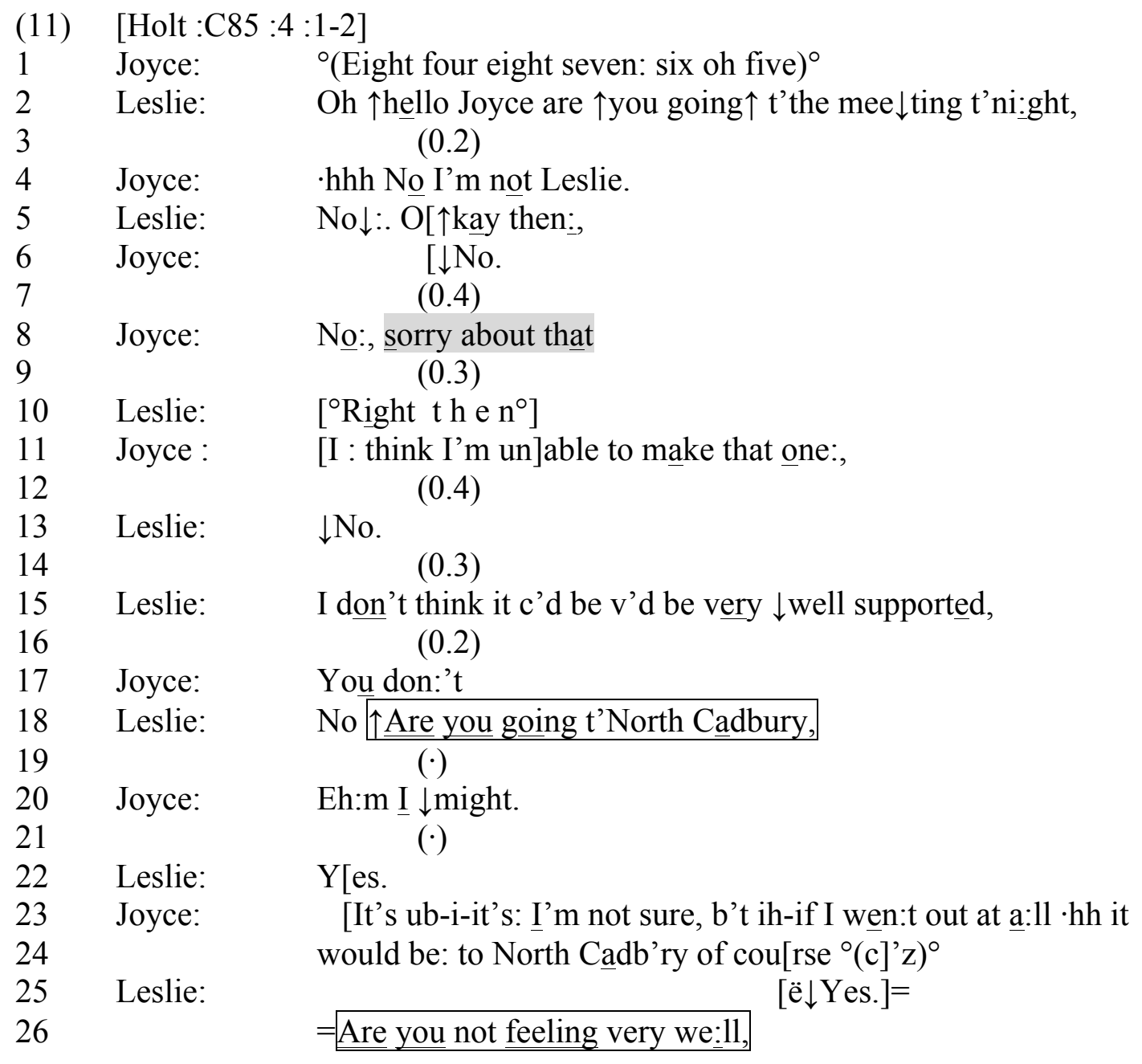

Leslie is the organiser of a local women's group, and is phoning round to find out who will be coming to a meeting; Joyce is a close friend, and has in the past been in Leslie's current role. Joyce's response in line 4 that she is not going to the meeting ('No I'm not Leslie') is simply that; it is unaccompanied by any apology for missing the meeting, or any account for doing so. To which Leslie responds with a simple acknowledgement (line 5) that does not progress the talk further. Joyce's subsequent turn is no more than a confirmation ('No' in line 6), repeated, after a pause, in line 8 to which she now adds an apology (highlighted). Joyce had opportunities to apologise 
before she does so, namely when she declares that she is not going to the meeting (in line 4) and again when she confirms that in line 6. There is evidence that Leslie is 'stalling', not progressing the interaction, in her acknowledgement in line 5 and in the silence in line 7. In her subsequent turns Leslie exhibits a certain expectation for more than a declaration from Joyce that she is not going, when, after Joyce formulates her not going as an inability ('unable to make ...') in line 11, she again acknowledges Joyce's declaration only minimally 'No' in line 13), then pursues the matter by asking for more information about what might account for Joyce's inability to go to the meeting, in lines 18 and 26. So having, after a delay, elicited an apology, Leslie pursues further an account for Joyce's failure to attend or support the meeting (line 15). The evidence from this is that in not progressing the interaction and in explicit inquiries about the reasons for another's conduct, a participant may treat the other's conduct as an apologisable and as accountable. Contrariwise, Joyce's delay in apologising, together with her evident reluctance to provide an account (from line 19 to the end of this excerpt) suggest that she takes a different view; they are misaligned about whether and to what extent Joyce has transgressed.

The participants in ex.12 seem similarly to orient to the non-progressivity of their interaction until an apology has been made. They are sisters; Sue has tried to call at the time they pre-arranged to talk, but evidently Mac had noted the time incorrectly, as midnight!

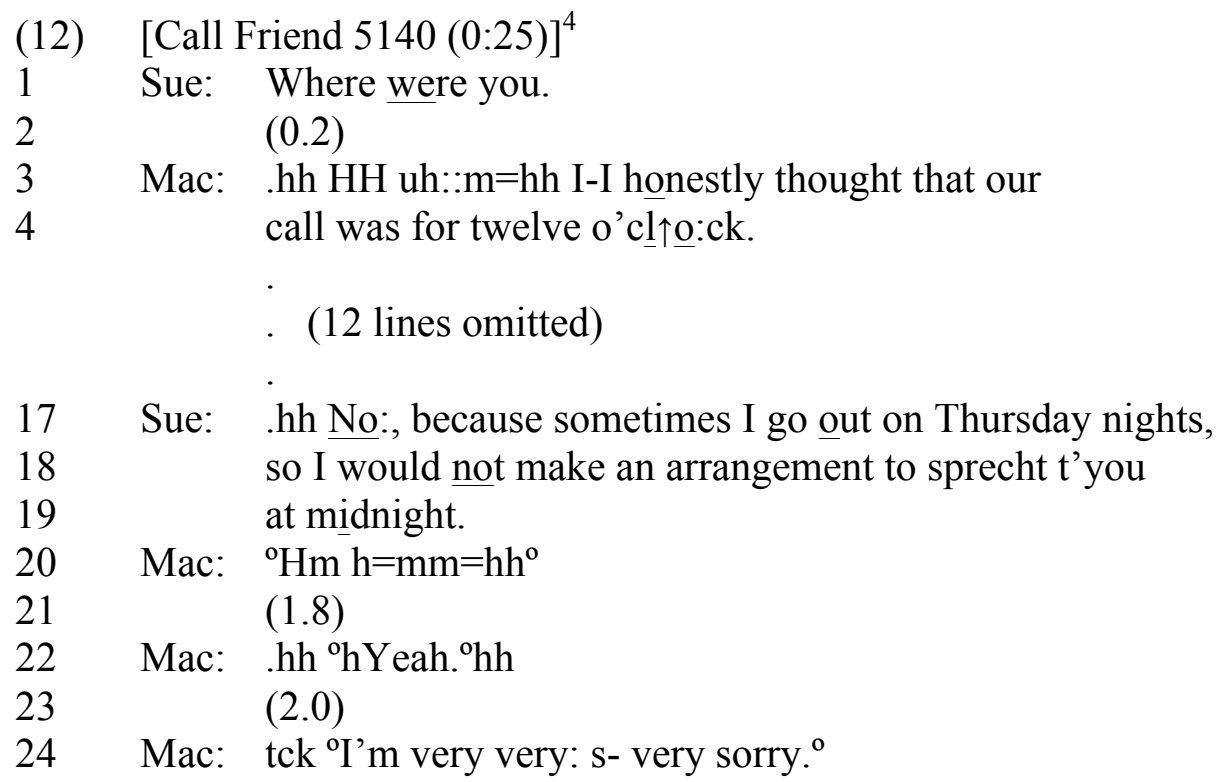

Sue's opening turn in this extract is a complainable matter. Mac's response is defensive (only the beginning is shown here), ${ }^{5}$ her defence seeming to be rejected by Sue ('No' followed by her explanation for why Mac must be wrong, lines 17-19). The ball is back in Mac's court; her minimal responses/acknowledgements in lines 20 and 22 are followed by lengthy pauses (on the interactional troubles manifest in conversation by pauses of over 1 second, see Jefferson 1989). Their conversation only progresses after Mac's eventual but fulsome apology in line 24 (and for a near identical example of a delayed apology, see Margutti et al. this issue, example 7). 
If we look again at the interaction between Gordon and Dana in ex.13, and back to the very beginning of the call, there is further evidence of a misalignment between them as regards the transgressive character of Gordon's conduct.

[Holt:88U:1:4:1-3,9-11]

Gordon: Hello:

(0.4)

Dana: $\quad$ Hello where'v you been all morning.=

Gordon: $\quad=$ hh HELLO! 'h Uh:m (0.3) thlk I've been: $(\cdot)$ at a music workshop.

$(\cdot)$

Gordon: $\quad \cdot t \cdot h h h h[h$

Dana:

[Oh:.

In Ansford.

$(0 . \overline{6})$

Gordon: How are you.

$(0.5)$

Dana: $\quad$ I['m okay

Gordon: $\quad[\cdot \operatorname{tplk}$

$(\cdot)$

Gordon: $\quad$ pk Good,

(0.5)

Dana: $\quad$ Actually I'm no[t but $(\cdot)$ the(h)re we go:, =

Gordon:

$[\cdot h h h$

$=$-hhhh ehhhhe:hh $\cdot$ hh But $(\cdot)$ yih $(\cdot)$ you are but you're not, $\cdot \mathrm{hh}[\mathrm{h}(($ sniff $))$ Hey listen I'm sorry about last ni:ght, $\cdot \mathrm{h} m \mathrm{hh}$

Dana:

Dana: [(Right)

[Mm:,

$[\cdot \mathrm{km} \cdot \mathrm{tch}$ I didn't think your mum would go $(0.5) \cdot \mathrm{pt} \cdot \mathrm{k}$ over the top,hh

In her opening in line 3 Dana plainly formulates her enquiry as a complainable matter (rather similar to the complainable matter in ex.12), in response to which Gordon makes a blocking move, his reciprocal 'hello' in line 4, before responding to Dana as though she had simply made an enquiry, that is without acknowledging the implicit complaint. He thereby passes by an opportunity to acknowledge and apologise for what he might understand to be the complainable matter (remembering what he did the night before). He then passes over other opportunities to acknowledge his 'wrongdoing' the previous night, notably when Dana's downgraded form response in line 13 ('I'm okay') might be taken to imply trouble (again, Jefferson 1980), an implication to which Gordon does not respond, in his mis-matched 'Good' (line 16). He comes to apologise only in line 21 , without, as we have seen, precisely admitting to what he is apologising for. And although his apology is in next position to Dana's clearer indication of trouble, 'Actually I'm not (okay)', line 18, his apology is made in a turn which is designed to be starting a new topic and therefore independent of Dana's (complainable) trouble, through the prefatory 'Hey listen' in line 21. In this way he is constructing his apology as done voluntarily, and not in response to Dana's pursuit of 'trouble'. There is further evidence that they are misaligned about his (mis)conduct when, after his account in lines 24 and 25 which attributes some responsibility to Dana's mother, Dana pursues the matter of the trouble he has caused 
and thereby does not accept his apology; after which 25 lines later he tries again with a similar apology, which again she does not accept, until 178 lines later he finally makes a full admission ('It was a bad move. . I was out of my brain at the time').

Such cases provide evidence that participants can be misaligned regarding the fault and/or culpability of a co-participant's (mis)conduct; that already in delays before an apology is proffered there is evidence for the absence of an apology; that a coparticipant may pursue an apology, an appropriate apology (admission), and an account for the other's (mis)conduct. What emerges from the design and components of an apology (see previous sections) and from this evidence of the (temporary) absence of an apology, and participants' pursuit of an apology and explanation (account), are differences between participants as regards whether or not one of them has transgressed, been at fault; and a normative framework for the expectations concerning what is due when they have transgressed. We will develop these issues by considering, finally, cases where an apology is not given.

\section{$\underline{\text { Absent apologies }}$}

In ex.2 above, Jessie responds "Oh dea:r." when Fortis told her that he tried to call her, as she requested, to make an appointment, but that he 'couldn't get any reply.' We observed that he responds ("T's alright" in line 6, ex.2) as though she had apologised. She has treated his news as a misfortune, but not a misdemeanour on her part; he, on the other hand, is treating her 'not replying' (not being at home?) as a little more than unfortunate - as representing some kind of fault in her conduct (along the lines, presumably, of her having asked him to call, then not being at home to receive his call). Although she did not apologise, he is responding to her turn as if she had - that is he is responding to an absent apology.

Referring to this as an absence conveys a normative phenomenon, that an apology might be due in a certain slot, but not forthcoming ('absence' being a formal, quasiinstitutional way of referring to 'expected to be but not present,' Drew \& Sorjonen 2011). To understand how "'T's alright" is a means to indicate that the previous turn was a slot in which an apology might have been given, but was not, consider where and how it is used in apology sequences, where a transgression is either contiguous or admitted.

(14) $\quad[$ Holt:C85:3:1] (Myra is not going to the meeting tonight)

1 Myr: I'm dreadf'ly sorry, [it's hhh ] hones]tly ah-ah- this=

2 Les: [That's $\uparrow$ al]ri:ght]

(15) [Holt:M88:1:5:7-8]

Robbie: $\quad \downarrow$ Sorry. I'm shouting at [my (

)] [个heh heh

2 Leslie:

I don't mind at all. $\cdot \underline{\operatorname{hhhhhh}[\mathrm{h} \text { aa- }}$

[That's alri:ght.] Th[at's alright.

(16) [Holt:X:(C):1:1:3:10-11]

$1 \quad$ Philip $: \rightarrow \quad$ I'M UH (.) I suh- sorry t'be a bit va:[gue I'm

2 Leslie: [That's alright don' worry 
'Okay' is also often used in this slot after an apology, as in these examples.

1 Rick: I:'m sorry I didn't call you last night.

2 Linny: That's okay,

In each of these cases a transgression is admitted, either before the excerpt (e.g. in ex.14), or in the apology turn, e.g. 'Sorry I'm shouting' in ex.15, 'I'm sorry to be vague' in ex.16, 'I'm sorry I didn't call you last night' in ex.17. Recipients accept the others' apologies either with 'alright' (examples 14-16) or 'okay' (example 17). There are variations between cases in which the acceptance is a 'stand alone' form or accompanied by another component (e.g. with 'that's, or with 'enhancements' such as "I don't mind at all" in ex.15 or "don' worry Philip" in ex.16, lines 2-3), which we can't explore further here. However, they have in common that they are all forms of accepting the apology by absolving the other of any wrongdoing. Robinson 2004:302305 reports that these two forms of absolution, 'That's alright' and 'That's okay', are the most common forms of acceptance of apologies (see also Owen 1983).

Examples 14-17 further illustrate our observation in the section above concerning the construction of apologies, that admissions are one of the core components of the turns in which speakers apologise to another. In these following examples speakers likewise admit to some mistake or wrongdoing (their admissions are highlighted in boxes). But in these cases their admissions are not accompanied by an apology.

(18) [NB:IV:10:22-23]

1 Lottie: Wuh I got tha:t wro:ng,

$2 \quad(\cdot)$

$3 \quad$ Emma: $\quad$ Oh that's $(\cdot){ }^{\circ}$ th:at's $\uparrow \underline{o} \downarrow$ kay $^{\circ} \cdot$ hhhhh

(19) [Holt:2:10:1-2] this is 103 in collection

1 Leslie: Uh:m (0.2) so I'm ringing you now cuz it's cheap rate t'l eight

4 Jeff: $\quad H m-h m$. heh heh. Til $\uparrow$ nine I think ih heh

$5 \quad$ Leslie: $\quad$ Til $\uparrow$ nine is it oh [I thought it w'z til $\downarrow$ eight.

6 Jeff: $\quad\left[\left({ }^{\prime}\right)\right.$

7 Jeff: $\quad$ Yahh. No it's alright Leslie

(20) [Holt :M88:1:5:11-12]

1 Robbie: Ye[s.

2 Leslie:

3 Robbie:

[Yes. Ye[h ·tch[ $\cdot \underline{h h}[$ hhhhh [Wuh-

4 Leslie:

[O k a[y, W'ddiyo[u wanna talk t'me abou(h) $[\mathrm{t}$ uh'clock isn't it.

$(\cdot)$ 


\begin{tabular}{|c|c|c|}
\hline 10 & Robbie: & $=$ haven't a:sked $\downarrow$ th'm. \\
\hline 11 & Leslie: & Oh: that's alrigh[t $\uparrow$ hhah hah hah hah $\uparrow[\cdot a h$ \\
\hline 12 & Robbie: & {$\left[\left({ }^{\prime}\right) \quad[\right.$ C'n I leave it another } \\
\hline 13 & & wee $: k$ \\
\hline 14 & Leslie: & $\cdot h h \bar{h}$ Well yes if you don't think it's too $\downarrow$ late no:w, \\
\hline 15 & Robbie: & Oh: no: $[$ no \\
\hline 16 & Leslie: & {$[$ No :, okay then } \\
\hline
\end{tabular}

(21) [TCI(b):9:2-3] (Larry has phoned his wife, Brenda, from work, to see how she's feeling - apparently she's got some sort of flu.)

1 Larry: Yeh $\underline{\mathrm{I}}$ j's call'tuh make sure you w'r yihknow, (0.2) ·hh I didn'

2 know whether you'd gone tih work er what yihkno[w,

3 Brenda: [I w'z ü-gu:n

4 tih go: tuh wor:k, hh I got a:fter you left $\underline{I}$ thought well I'll eat

5 s'm brekf'ss en then a w'l go: tuh wor:k.hh

(8 lines omitted)

$\begin{array}{lll}13 & \text { Larry: } & \text { Mm hm, } \\ 14 & \text { Brenda: } & \begin{array}{l}\text { hhh En then I gotta real bad stomach ache. } \\ (1.7)\end{array} \\ 15 & & \text { Like }(\cdot) \text { when }(\cdot) \text { somew'n tied a knot in my stomach. } \\ 16 & \text { Brenda: } & (0.2) \\ 17 & & \text { hhh So I lay dow:n en the next thing I know it was eleven } \\ 18 & \text { Brenda: } & \text { uh'clo:hh- } \\ 19 & & \text { hh heh-heh-heh-heh-heh-hih-hih-heh= } \\ 20 & \text { Larry: } & =\text { So I din' go:. } \\ 21 & \text { Brenda: } & \text { Ah, } \\ 22 & \text { Larry: } & (0.3) \\ 23 & & \text { No that's: okay, } \\ 24 & \text { Larry: } & (0.5) \\ 25 & & \text { Mh, } \\ 26 & \text { Larry: } & (1.2) \\ 27 & & \text { They g'n get along without yih fer a day er two, } \\ 28 & \text { Larry: } & \end{array}$

The admissions may be brief, as in examples 18 and 19, or they may be elaborated, for instance with 'to be honest' prefaces (in example 20; see Edwards and Fasulo 2006), or accompanied by narrative explanations and accounts (ex.21). But whether or not the admissions of a wrongdoing are 'simple' or elaborated, the pattern is the same; a speaker admits to some misdeed, but goes no further - does not apologise, nor offer any account after the admission; in response to which the recipient absolves them (highlighted by shading). Since absolution is the appropriate action with which to accept an apology, absolution without an apology having been made treats the other as though they had apologised.

With that pattern in hand, we should return to the absent apology shown in our introduction in ex.2, here reproduced in its fuller context from the beginning of the call in which Jessie telephones her optician. Evidently she called in at their premises "on Thursday:" (lines 2/3) to see if she could make an appointment, and was 
expecting to hear back from the optician, Mr Fortis, but "I haven't heard anything" (line 6).

\begin{tabular}{|c|c|c|}
\hline \#22 & \multicolumn{2}{|c|}{ [Rahman:1:2:1] (Jenny phones her opticians) } \\
\hline 1 & Desk: & Hello Goodwin, \\
\hline 2 & Jessie: & Ehm good morning. eh it's Missiz Cha:ndra here, I ca:lled in on \\
\hline 3 & & Thursday: to see: if uh I c'd make en appointment t'see Mister \\
\hline 4 & & Fortis, \\
\hline 5 & & $(1.2)$ \\
\hline 6 & Jessie: & An', I haven't heard anything 'n I w'z wond'ring if: uh:m \\
\hline 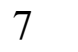 & & (Mister Fortis c'd see me) one day next week. \\
\hline & & $(0.8)$ \\
\hline$y$ & Desk: & Uh:m I'll j's check iz diary c'n you hold a minute (eh [please). \\
\hline 10 & Jessie: & $\begin{array}{c}{[Y e s,} \\
\text { ((ca } 9 \text { lines omitted, receptionist asking for caller's name)) }\end{array}$ \\
\hline 19 & & $(7.0)$ \\
\hline 20 & Fortis: & Hello::: \\
\hline 21 & Jessie: & Hello? \\
\hline $\begin{array}{l}22 \\
23\end{array}$ & Fortis: & $\begin{array}{l}\text { I tried tuh ring you on: Thursday evening. }=\text { b't I couldn' get'ny } \\
\text { reply::. }\end{array}$ \\
\hline 24 & Jessie: & Oh dea:r. ehh hnh[h \\
\hline 25 & Fortis: & ['T's alright [Now? \\
\hline 26 & Jessie: & {$[\cdot h \overline{h h}$} \\
\hline 27 & & $(\cdot)$ \\
\hline 28 & Fortis: & [uh:: \\
\hline 29 & Jessie: & [eh Yes. \\
\hline 30 & Fortis : & When dihyou wan'tuh come in Monda:y? \\
\hline
\end{tabular}

Jessie's account in lines 2-6, culminating in "I haven't heard anything," is formulated as a complainable matter. Whilst the receptionist says that she'll check Fortis's diary, actually she fetches him to the phone (line 20). Without identifying himself, in response to her try-marked "Hello?", Fortis straightaway informs Jessie that he tried to contact her, but 'could get any reply,' indicating that he did what he was asked to do, and therefore that any 'failure' was not his but Jessie's (not that 'there was no reply' but that "I couldn't get any reply). Jessie's response, "Oh dea:r" highlighted in line 24 , is to treat this as a misfortune; she does not admit to any wrongdoing. Nevertheless his response in line 25 to hers in line 24 is to absolve her of wrongdoing (highlighted), as though she had admitted and apologised for not being at home to take his call. In these few lines they are engaged in a tussle over which of them is at fault, neither admitting to any wrongdoing or failure; Jessie is content to treat the outcome as a misfortune, whilst Fortis pursues the matter of some failure on her part, whilst absolving her of that failure. This is precisely the territory of the negotiation of culpability that we noted above.

\section{Conclusion}

The phenomenon of absent apologies - the expectation that an apology is due, though that apology is not forthcoming - is a common enough experience; we recognise such situations in our ordinary lives, ${ }^{6}$ and the media report them widely. 
Media reports such as that shown in ex.3 highlight the link between admissions of wrongdoing and apologies - through their symbiotic absence; that is, refusals to apologise accompany denials of wrongdoing. We have explored the evidence that apologies might not merely be absent but be noticeably absent for participants in ordinary interactions. The evidence is circumstantial. The first kind of evidence is the delays that can occur in the progressivity in talk, until an apology is forthcoming, as illustrated in examples 11-13, in which there are indications that a speaker may pursue some matter (e.g. her friend not coming to a meeting) until an apology and indeed an explanation are forthcoming. The second kind of evidence is that speakers can treat the other's prior turn as though it had been an apology. Deriving from our analysis of the components through which apology turns are constructed, namely [Admission of a transgression] + [Apology], sometimes accompanied by an [Account], when a speaker admits to some mistake or wrongdoing but without apologising, their recipient may absolve them of culpability, just as they would have done if the other had apologised.

\section{$\underline{\text { References }}$}

Atkinson, J.M. \& Drew, P. (1979) Order in Court: The Organisation of Verbal Interaction in Judicial Settings. London, Macmillan.

Clift, R. (2001) Meaning in interaction: the case of actually. Language, 77:245-291.

Drew, P. and Sorjonen, M-L. (2011) Dialogue in institutional interactions. In T. van Dijk (ed.) Discourse Studies: a Multidisciplinary Introduction. London, Sage:332378.

Edmondson,W.J. (1981) On saying you're sorry. In F.Coulmas (Ed.) Conversational Routines, The Hague, Mouton: 273-288.

Edwards, D. \& Fasulo, A. (2006) 'To be honest': Sequential uses of honesty phrases in talk-in-interaction. Research on Language \& Social Interaction, 39: 343-376.

Goodwin, C. (1980) Restarts, pauses and the achievement of a state of mutual gaze at turn-beginning. Sociological Inquiry, 50: 272-302.

Hastie, B. \& Augoustinos, M. (2012) Rudd's apology to the stolen generations: challenging self-sufficient arguments in 'race' discourse. Australian Psychologist, 47: 118-126.

Heritage, J. \& Raymond, C. (this issue) Are explicit apologies proportional to the offenses they address? Discourse Processes, vol + pages.

Jefferson, G. (1980) On ‘trouble-premonitory' response to inquiry. Sociological Inquiry, 50:153-185.

Jefferson, G. (1987) Remarks on non-correction in conversation. Unpublished lecture to the Department of Finnish, University of Helsinki, Finland. 
Jefferson, G. (1989) Notes on a possible metric which provides for a 'standard maximum' silence of approximately one second in conversation. In D. Roger and P. Bull (Eds. Conversation; An interdisciplinary perspective. Clevedon, UK:

Multilingual Matters: 166-196.

Margutti, P., Pugliese, R., \& Traverso, V. I'm sorry 'about that': apologies, indexicals and unnamed offenses. Discourse Processes, vol + pages.

Owen, M. (1983) Apologies and Remedial Interchanges: A study of Language Use in Social Interaction. Berlin, Mouton.

Pino, M., Pozzuoli, L., Riccioni, I. \& Castellarin, V. (date) Oh-prefaced apologies: a practice for managing the concomitant presence of a possible offense and problem-tobe-solved. Discourse Processes, vol + pages

Robinson, J. (2004) The sequential organization of 'explicit' apologies in naturally occurring English. Research on Language \& Social Interaction, 37:291-330.

Rossi, G. (2015) When do people not use language to make requests? In P.Drew and E.Couper-Kuhlen (Eds.) Requesting in Social Interaction. Amsterdam, Benjamins: 305-336.

Schegloff, E.A. (1988) Goffman and the analysis of conversation. In P.Drew and A.J. Wootton (Eds.) Erving Goffman: Exploring the Interaction Order. Cambridge, Polity Press, 89-135.

${ }^{1}$ For an interestingly complex example covered in the media, concerning whether or not an apology should be made for 'historical' wrongdoings, see Hastie \& Augoustinos (2012).

2 “(h)uhm" in line 1 of ex.4 is 'I'm', spoken in laughter.

${ }^{3}$ This is a play on words; Emma suggested to her husband that he take the power tool down on Friday (day of the week) to the 'Fridays', which happens to be the last name of Margy and her husband. Her reference 'nine books' and the 'stamp place' is to a system for saving 'points' in the form of stamps which were given for purchases in certain stores (in the UK Green Shield stamps were perhaps the best known). These stamps were stuck in a book, and books could then be traded for goods at a 'stamp place'.

${ }^{4}$ We are grateful to Galina Bolden for drawing our attention to this example.

${ }^{5}$ On 'honestly' constructions, see Edwards \& Fasulo, 2006.

${ }^{6}$ It should not be forgotten that we have to learn to apologise; children are reminded and encouraged or instructed to say 'sorry' in circumstances that should oblige a miscreant to apologise to whoever he or she has harmed. 